\title{
Does gastric aminopyrine clearance reflect gastric mucosal blood flow or parietal cell function?
}

\author{
S A MÜLLER-LISSNER,* A SONNENBERG, AND A L BLUM \\ From the Triemli Hospital, Zurich, Switzerland
}

SUMMARY Gastric aminopyrine clearance was measured in human volunteers and dogs with untreated basal secretion, in human volunteers and dogs treated with secretory inhibitors, in dogs treated with histamine, and in patients with pernicious anaemia. When aminopyrine was given as a bolus to man or dog, aminopyrine clearance and the ratio aminopyrine concentration in gastric juice/aminopyrine concentration in plasma showed an initial peak two to three times over steady state levels. When aminopyrine was given with histamine, the peaks were even higher. No peaks occurred when an aminopyrine bolus was given to patients with pernicious anaemia or to healthy volunteers treated with secretory inhibitors. The height of the peaks paralleled the acid secretory rate. The peaks may best be explained by aminopyrine accumulation in the parietal cells and washing out of aminopyrine by volume flow. The steady state levels might reflect both parietal cell function and gastric mucosal blood flow.

It is widely accepted that gastric aminopyrine clearance reflects gastric mucosal blood-flow. ${ }^{1-4}$ It is assumed that the gastric mucosa functions like a dialysis membrane between the neutral plasma and the acidic gastric juice. ${ }^{25}$ Thus, the only rate limiting factor for aminopyrine clearance would be gastric mucosal blood flow. We have, however, in isolated dispersed gastric parietal cells observed considerable trapping of aminopyrine in the intracellular canaliculus. ${ }^{6}$ Thus, the gastric mucosa would not be a simple dialysis membrane but would also store-and eventually release-aminopyrine. The storage capacity within the parietal cell would depend on intracellular acidity and thus parietal cell function. In addition, transient aminopyrine trapping could also occur in an unstirred layer covering the mucosa, including, among other structures, the glandular lumen. In order to test the assumption that aminopyrine clearance solely reflects mucosal blood flow, a series of experiments was done in man and dogs under basal conditions, with gastric secretion stimulated with histamine and restrained with anti-secretory agents. As the observations cannot be explained by blood flow alone and as aminopyrine clearance parallels acid secretion rate,

*Address for correspondence: S A Müller-Lissner, Triemli Hospital Birmensdorferstr. 497, CH-8063 Zürich. Switzerland.

Received for publication 8 May 1981 aminopyrine clearance appears to reflect in part parietal cell function.

\section{Methods}

STUDIES IN MAN

After an overnight fast, a double lumen gastric tube was positioned under fluoroscopic control with its tip in the antrum. Gastric juice was collected by intermittent suction using an Egnell pump model EMP 171 687. Fasting gastric contents were removed during 15 minutes. Then, the stomach was perfused at a rate of $1.5 \mathrm{ml} / \mathrm{min}$ using a Harvard pump model 975. The perfusion fluid contained $100 \mathrm{mM} \mathrm{HCl}$ and $2 \%$ polyethylene glycol 4000 (Siegfried, Switzerland). In order to insure patency of the aspiration port manual aspiration was performed every five minutes and a small bolus of air was given at that time. The gastric aspirates were pooled in 15 minute fractions.

(Dimethyl-1 ${ }^{14} \mathrm{C}$ )-aminopyrine was obtained from New England Nuclear. Its specific activity was $100 \mathrm{mCi} / \mathrm{mM}$. At time zero, after aspiration of the fasting gastric juice, an intravenous ${ }^{14} \mathrm{C}$-aminopyrine bolus $(8 \mu \mathrm{Ci})$ was given. This was followed by an intravenous infusion for three hours at a rate of $2 \mu \mathrm{Ci} / \mathrm{h}$. For this purpose, aminopyrine was dissolved in normal saline $(2 \mu \mathrm{Ci} / 100 \mathrm{ml}$ of saline, infusion rate $150 \mathrm{ml} / \mathrm{h}$ ). A winged needle with a heparin lock was positioned in a cubital vein. Blood samples were obtained as shown in Fig. 1. The blood was collected in tubes containing EDTA. 


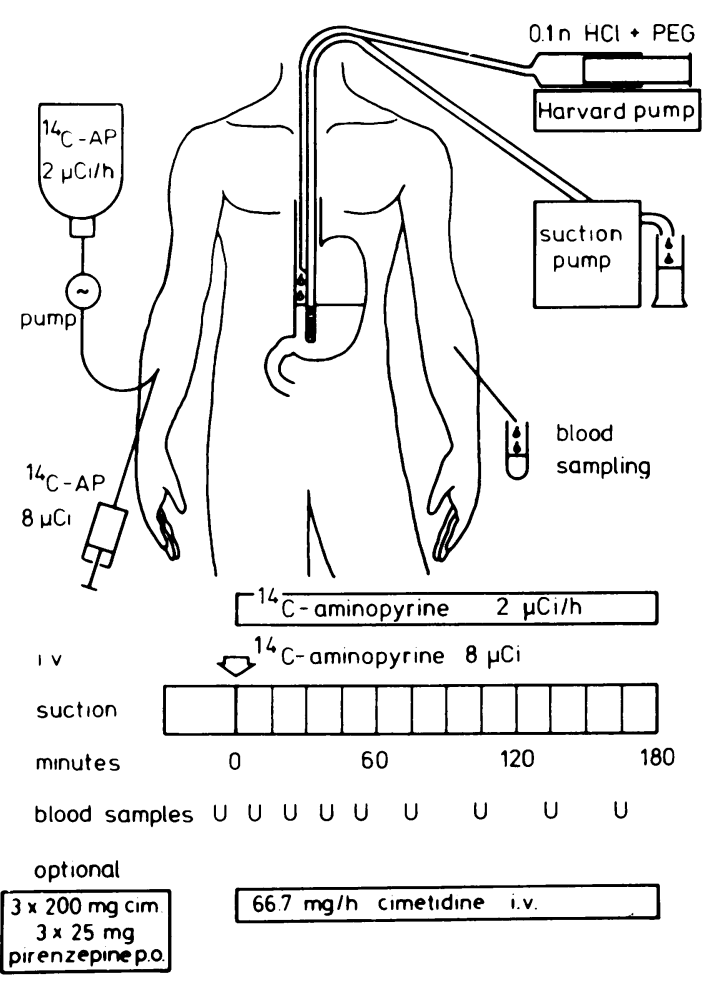

Fig. 1 Experimental procedure. For details see text.

STUDIES IN DOGS

In nine dogs, Komarov type oesophagostomies were constructed under general anaesthesia. The Komarov oesophagostomies allowed easy insertion of gastric tubes but did not interfere with food and fluid intake. The experiments were started four weeks after completion of surgery. The experimental procedure resembled that in man (Fig. 1).

ASSA Y S

Aminopyrine was extracted from plasma and gastric juice by dichlormethane as described by Tague and Jacobson". Samples were counted for "C-radioactivity in a liquid scintillation counter. Appropriate corrections were made for the calculation of $\mathrm{dpm} / \mathrm{ml}$. The polyethylene glycol concentration of the gastric aspirates was measured by photometry after protein precipitation by cold acetone as described by Buxton ${ }^{\circ}$. The acid concentration in the gastric juice was determined by titration with $\mathrm{NaOH}$ in 0.01 molar concentration. For the calculation of the amount of acid secreted the appropriate amount of
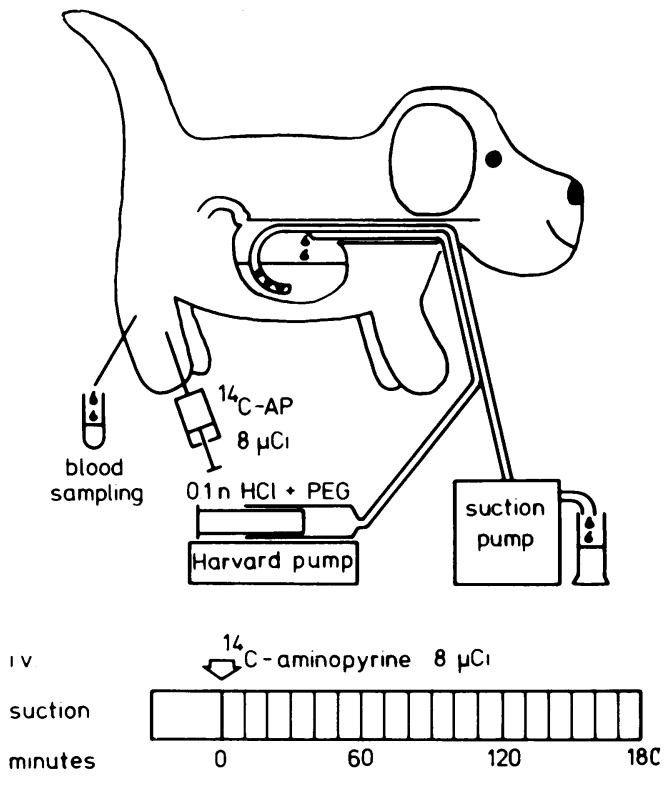

blood samples $U \cup \cup \cup \cup \cup \cup U \in U U U$

optional

\begin{tabular}{|ll|}
$3 \times 200 \mathrm{mg}$ cim.po. & $667 \mathrm{mg} / \mathrm{h}$ cimetidine iv. \\
or & $60 \mathrm{\mu g} / \mathrm{kg} / \mathrm{h}$ histamine iv. \\
\hline
\end{tabular}

infused acid was substracted. The aminopyrine clearance in $\mathrm{ml}$ min is given by $\mathrm{RV}$ where $\mathrm{R}=$ aminopyrine concentration of the gastric juice/ aminopyrine concentration of the plasma and $\mathrm{V}$ is the net secretion volume per minute.

\section{STATISTICS}

The values of aminopyrine clearance and $R$, respectively, were compared by Student's $t$ test. Paired tests were used when appropriate. Changes in the concentration of ${ }^{11} \mathrm{C}$ in plasma and gastric juice, respectively, were compared with zero $(=$ no change) by paired $t$ tests. The relation between mean acid output and maximum of aminopyrine clearance was examined by linear regression analysis.

SUBJECTS STUDIED

The study protocol was approved by the local ethical committee.

Healthy human volunteers

a. Basal secretion Eight volunteers were studied. 
b. Treatment with secretory inhibitors In six subjects, $200 \mathrm{mg}$ cimetidine and $25 \mathrm{mg}$ pirenzepine were given eight, four, and two hours before the beginning of the experiment. In addition, an intravenous infusion of cimetidine was given during the experiment at a dose of $66.7 \mathrm{mg} / \mathrm{h}$.

\section{Patients with pernicious anaemia}

In four otherwise healthy subjects with pernicious anaemia (age 68, 72, 79, and 91 years) informed consent was obtained to perform the experiments as outlined above. No cimetidine or pirenzepine was administered.

\section{Dogs}

a. Basal secretion Each dog was studied once (=- nine experiments) without additional treatment.

b. Treatment with histamine In four experiments dogs received histamine dihydrochloride $(60 \mu \mathrm{g}$ $\mathrm{kg} / \mathrm{h}$ intravenously) 60 minutes before gastric juice aspiration was started and the infusion lasted for the duration of the experiment.

c. Treatment with secretory inhibitors Three dogs were treated with cimetidine given orally $(400 \mathrm{mg}$ eight hours and $200 \mathrm{mg}$ two hours before each experiment) and then by intravenous infusion $(66.7 \mathrm{mg} / \mathrm{h}$ during the study).

\section{Results}

${ }^{14}$ C RADIOACTIVITY IN PLASMA AND GASTRIC JUICE

Curves were obtained by connecting two consecutive points of gastric juice and of plasma aminopyrine concentr ation. The slopes were different from zero for the gastric juice curve in man during the first 60 minutes, for the plasma curve in man for the first 15 minutes, for the gastric juice curve in the dog for the first 90 minutes, and for the plasma curve in the dog for the first 10 minutes, respectively (Fig. 2). In the histamine treated dogs the slope of the gastric juice curve was different from zero during the first 60 minutes, the slope of the plasma curve during 10 minutes, respectively. In man and dog treated with secretory inhibitors and in patients with pernicious anaemia the slopes of the gastric juice curve were never different from zero, while the slopes of the plasma curves differed from zero during the first experimental period (in man 15 minutes and in dogs 10 minutes, respectively). Thus, ${ }^{14} \mathrm{C}$-concentration in plasma always drops during the first 10 to 15 minutes after the bolus injection and then reaches a steady state. In gastric juice, however, occurrence and duration of changes in ${ }^{14} \mathrm{C}$-concentration depend on the secretory state of the stomach.

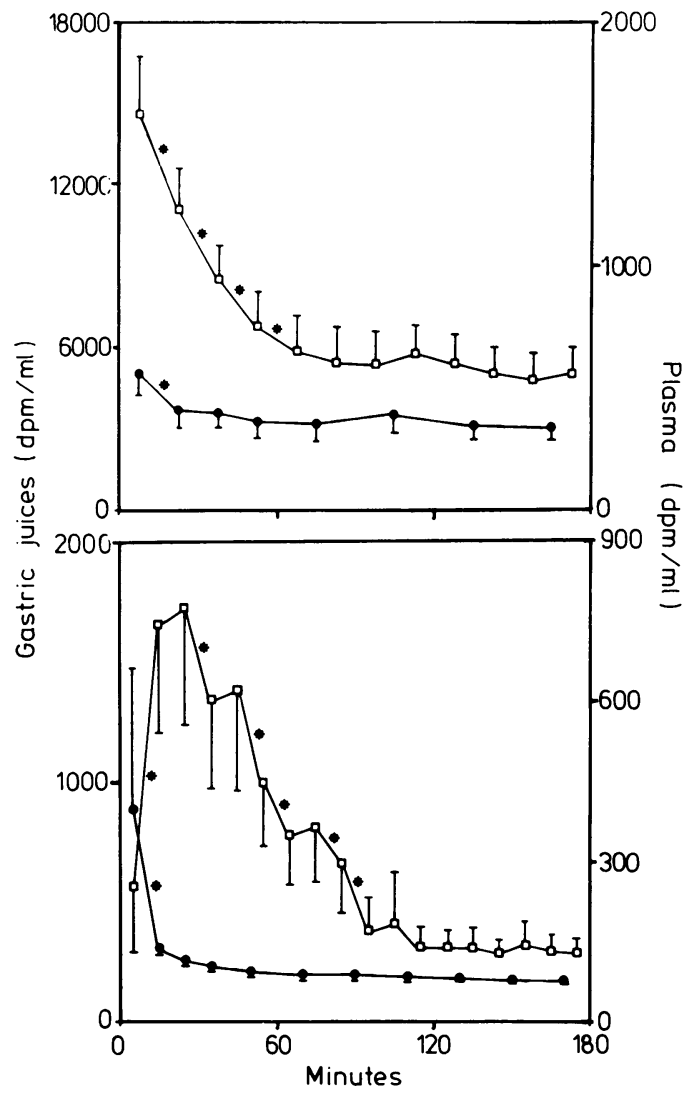

Fig. $2{ }^{14}$ C radioactivity in plasma $(\bullet-0)$ and gastric juice (__ Top: volunteers under hasal conditions. Bottom: dogs under basal conditions.

AMINOPYRINE CLEARANCE VALUES IN

MAN AND DOG

Marked initial peaks are noted in human controls and in histamine treated dogs (Fig. 3). In histamine treated dogs the peak is higher and occurs earlier than the peak in untreated dogs $(\mathrm{P}<0.05)$ where peaks are also noted. In volunteers treated with cimetidine and pirenzepine, in patients with pernicious anaemia, and in dogs treated with cimetidine no peaks occur. Similar observations were obtained for the $R$ values (Table).

RELATION BETWEEN AMINOPYRINE

CLEARANCE AND ACID SECRLTION

When the mean acid output is compared with the maximal value of the aminopyrine clearance, a linear correlation is obtained in man (Fig. 4) and $\operatorname{dog}(y=12.7+34.6 x, \quad r=0.82, \quad n=16, \quad P<0.01)$. Similar observations were made for mean acid output and the steady state values of the amino- 
Table Values for ratio aminopyrine concentration in gastric juice/aminop.rine concentration in plasma in man and dog (means $S E M$ )

\begin{tabular}{|c|c|c|}
\hline Groun & Maximum & Steady state \\
\hline $\begin{array}{l}\text { Man } \\
\text { Basal (control) } \\
\text { Secretory inhibition } \\
\text { Pernicious anaemia }\end{array}$ & 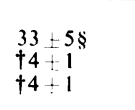 & $\begin{array}{r:c}15 & 5 \\
4 & 2^{*} \\
4 & 1^{*}\end{array}$ \\
\hline $\begin{array}{l}\text { Dog } \\
\text { Basal (control) } \\
\text { Histamine stimulation } \\
\text { Secretory inhibition }\end{array}$ & $\begin{array}{c:c}15 & 4 \$ \\
23 & 9 \$ \\
9 & 1\end{array}$ & $\begin{array}{l:l}5 & 1 \\
6 & 1 \\
6 & =1\end{array}$ \\
\hline
\end{tabular}

* $P \leqslant 0.05, \dagger P<0.01$ when compared with basal, § significantly higher than steady state level.

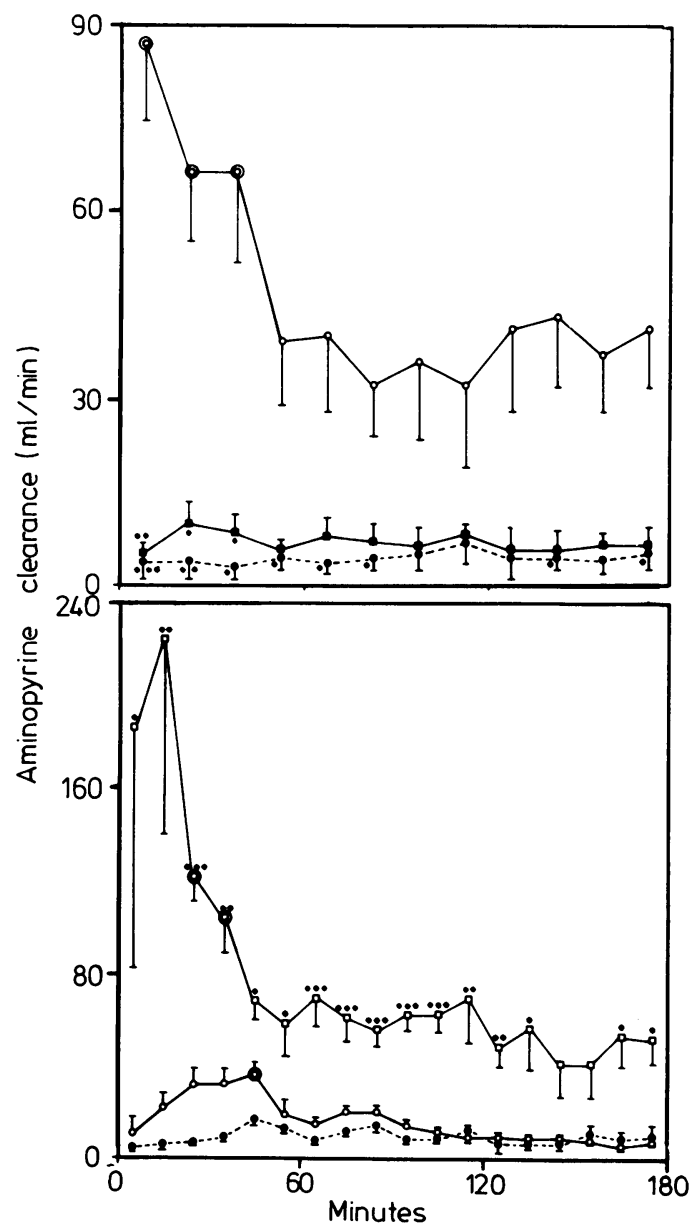

Fig 3 Aminopyrine clearance values. Top: man. $\bigcirc-\bigcirc$ volunteers under basal conditions; treated with secretory inhibitors; volunteers pernicious anaemia. Bottom: dogs. $\bigcirc-\bigcirc$ under basal conditions; - treated with secretory inhibitors; $\square-\square$ treated with histamine. Means $\pm S E M$. $*_{\mathrm{P}}<0.05,{ }^{*} *_{\mathrm{P}}<0.01, * * * *_{\mathrm{P}}<0.001$. Encircled values are significantly higher than steady state levels $(\mathrm{P}<0.05)$.
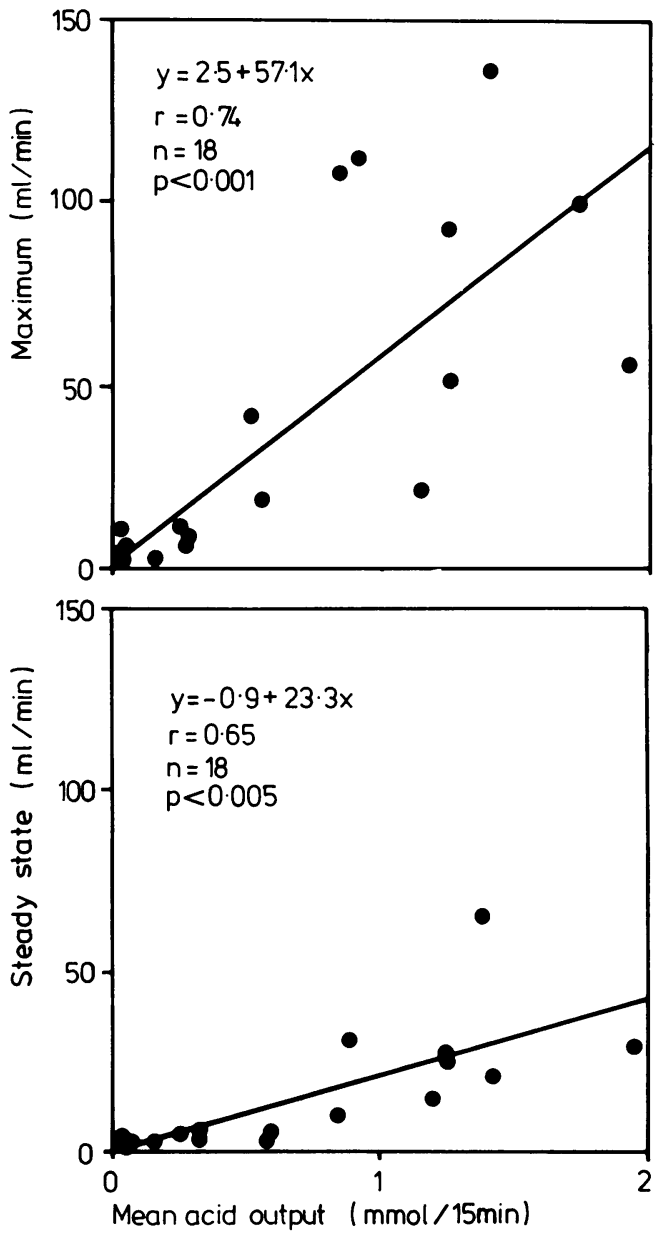

Fig. 4 Linear regression analysis comparing mean acid output with the maximal value (top) and with the steady state value (bottom), respectively, of aminopyrine clearance in man.

pyrine clearance (Fig. 4 and $\mathrm{y}=11 \cdot 1 \div 5 \cdot 0 \mathrm{x}, r=0 \cdot 84$, $\mathrm{n}=16, \mathrm{P}<0.01$, respectively). Thus, aminopyrine clearance and acid output (in $\mathrm{ml} / \mathrm{mmol}^{+}$) are related in both analyses but the ratio is higher during maximal clearance than during the steady state $(803-152$ vs. $304+65, \mathrm{P}<0.01$, in man, and $452 \div 142$ is. $76-14, \mathrm{P}<0 \cdot 01$, in dogs). Thus, the ratio is not a measure for the blood flow required to produce a millimole of $\mathrm{H}^{+}$.

\section{Discussion}

Aminopyrine, like neutral red and other substances cleared by an acid partition mechanism, 589 is widely used for determination of gastric mucosal 
blood flow. ${ }^{1-410}$ Its main advantage over other methods, such as ${ }^{4 "} \mathrm{~K}$-clearance, "Rb-clearance, and mucosal accumulation of radiolabelled microspheres, is the ease of in rivo measurements in animals and $\operatorname{man}^{1}{ }^{11}$. In the present study we investigated whether gastric mucosal blood flow is the only determinant of gastric aminopyrine clearance. As shown by Figs. 2 and 3 and the Table this is clearly not the case. Peaks of $\mathrm{R}$ and of aminopyrine clearance are observed during the first 6) to 120 minutes, both in healthy man and dogs. Interestingly, they were high in untreated man who is known to have a relatively high basal secretion. They were lower in untreated dogs where basal secretion is low but very high in dogs stimulated with histamine. They were absent in man and dogs treated with secretory inhibitors and also in achlorhydric patients with pernicious anaemia. Thus, the time course of gastric aminopyrine clearance cannot be explained by blood flow. A good explanation for the observed peaks is aminopyrine trapping in parietal cells and washing out by volume flow across the parietal cells. This explanation appears likely because a steady state of ${ }^{11} \mathrm{C}$-aminopyrine concentration occurs later in the gastric juice than in plasma while the stomach secretes (Fig. 2). The finding that the steady state levels depend on acid secretion (Fig. 4) is compatible with the classical model that aminopyrine clearance reflects gastric mucosal blood flow. As, however, peaks occur only in the secreting stomach, they cannot be explained by blood flow. Thus, the peaks might reflect parietal cell function and the steady state levels might reflect both parietal cell function and gastric mucosal blood flow.

Other authors have already given evidence for shortcomings of the aminopyrine method. ${ }^{11-14}$ Archibald et al. ${ }^{12}$ compared aminopyrine clearance with blood flow measurements obtained by the microsphere technique. They reported that, in the nonstimulated canine stomach, aminopyrine clearance reflects only a small fraction of the gastric mucosal blood flow, whereas during histamine stimulation the two methods give similar results. Moody ${ }^{11}$ compared aminopyrine clearance with 1"K-clearance. During thiocyanate inhibition aminopyrine clearance paralleled acid secretion but did not reflect the blood flow changes measured by the ${ }^{12} \mathrm{~K}$-clearance. Delainey et al. ${ }^{13}$ measured the effect of cimetidine on gastric mucosal blood flow by a microsphere technique. They did not observe a decrease of the gastric mucosal blood flow, in contrast with Konturek ${ }^{3}$ who observed a reduction of the aminopyrine clearance under similar experimental conditions. No reduction was obtained by a neutral red clearance technique. ${ }^{15}$ It has also been reported that the clearance values with aminopyrine do not reach steady state in the first hour of an experiment, " '" but these findings, so far, have not received further consideration. Finally, Dugas et al. ${ }^{16}$ have given evidence that the aminopyrine clearance is not only limited by blood flow, but also by diffusion.

In conclusion, aminopyrine clearance appears to reflect both gastric mucosal blood flow and parietal cell function. As in many instances there is a parallel change of gastric mucosal blood flow and of parietal cell function, changes in aminopyrine clearance has the following limitations: (1) it is only a relative measure of gastric mucosal blood flow; (2) steady state conditions in plasma and gastric juice are required; and (3) the acid secretion rate should remain constant during the experiment.

This work was presented at the annual meeting of the AGA 1980 in Salt Lake City. An abstract appeared in Gastroenterology 78: 1227, 1980. Supported by Swiss National Foundation grant no. 3.158-0.77. The technical assistance of $\mathrm{Mrs} \mathrm{M}$ Berger and Mrs $M$ Lukachich is gratefully acknowledged.

\section{References}

${ }^{1}$ Guth PH, Bauman H, Grossman MI, Aures D, Elashoff J. Measurement of gastric mucosal blood flow in man. Gastroenterology 1978; 74: 831-4.

${ }^{2}$ Jacobson ED. Clearances of the gastric mucosa. Gastroenterology 1968; 54:434-8.

${ }^{3}$ Konturek SJ, Tasler J, Obtulowicz W, Rehfeld JF. Effect of metiamide, a histamine $\mathrm{H}_{2}$-receptor antagonist, on mucosal blood flow and serum gastrin level. Gastroenterology 1974; 66: 982-6.

'Tague LL, Jacobson ED. Evaluation of ${ }^{14} \mathrm{C}$-aminopyrine clearance for determination of gastric mucosal blood flow. Proc Soc Exp Biol Med 1976; 151: 707-10.

'Shore PA, Brodie BB, Hogben CAM. The gastric secretion of drugs: a $\mathrm{pH}$ partition hypothesis. $J$ Pharmacol Exp Ther 1957; 119:361-9.

"Sonnenberg A, Berglindh T, Lewin MJM, et al. Stimulation of acid secretion in isolated gastric cells. In Rosselin G, Fromatgeot P, Bonfils S, eds. Hormone receptors in digestion and nutrition. Amsterdam: Elsevier North Holland Biomedical Press, 1979: 337-48.

'Buxton TB, Crockett JK, Moore WL, et al. Protein precipitation by acetone for the analysis of polyethylene glycol in intestinal perfusion fluid. Gastroenterology 1979; 76: 820-4.

"Aures D, Guth PH, Grossman MI. Use of neutral red to measure gastric mucosal blood flow. Gastroenterology. 1975; 68: 1057.

${ }^{9} \mathrm{Knight} \mathrm{SE}$, McIssac RL. Neutral red clearance as an estimate of gastric mucosal blood flow in dogs. $J$ Physiol (Lond) 1977; 267:45-4.

${ }^{10}$ Rudick J, Werther JL, Chapman ML, et al. Mucosal 
blood flow in canine antral and fundic pouches. Gastroenterology 1971; 60:263-71.

${ }^{11}$ Sonnenberg A, Blum AL. Limitations to measurement of gastric mucosal blood flow by ${ }^{14} \mathrm{C}$-aminopyrine clearance. In: Fielding LP, ed. Gastrointestinal mucosal blood flow. Edinburgh: Churchill Livingstone, 1980: 43-58.

${ }^{12}$ Archibald LH, Moody FG, Simons MA. Comparison of gastric mucosal blood flow as determined by aminopyrine clearance and $\gamma$-labelled microspheres. Gastroenterology 1975; 69: 630-5.

${ }^{13}$ Delaney JP, Michel HM, Bond J. Cimetidine and gastric blood flow. Surgery 1977; 84: 190-3.
${ }^{14}$ Moody FG. Oxygen consumption during thiocyanate inhibition of gastric acid secretion in dogs. $\mathrm{Am} \mathrm{J}$ Physiol 1968; 215: 127-31.

${ }^{15} \mathrm{Knight} \mathrm{SE}$, Mclssac RL, Rennie CD. The effect of histamine and histamine antagonists on gastric acid secretion and mucosal blood flow in man. Br J Surg 1980; 67: 266-8.

${ }^{16}$ Dugas MC, Weschler RL. Analysis of aminopyrine clearance to measure gastric mucosal blood flow: insight derived from mathematical models. In: Fielding LP, ed. Gastrointestinal mucosal blood flow. Edinburgh: Churchill Livingstone, 1980: 35-42. 